\title{
Chapter 9 \\ How to Make the Life Cycle Assessment Team a Business Partner
}

\author{
Mark Goedkoop, Eric Mieras, Anne Gaasbeek, and Soledad Contreras
}

\begin{abstract}
In this chapter we explore the need and opportunities to make the life cycle assessment (LCA) team more relevant for the business. Sustainability trends and alternatives for LCA are analyzed to identify what makes them relevant for and appealing to business managers, the difficulties LCA practitioners face to get their message across have been identified, and a five-step approach to make the LCA team a business partner will be described. The goal is to empower LCA teams and practitioners to create sustainable value for the business they work in.
\end{abstract}

Keywords Champion for LCA • Circular economy $\bullet$ LCA community $\bullet$ LCA team - Life cycle assessment • Life cycle management • Product sustainability • Sustainability

\section{Introduction: 20 Years of Life Cycle Assessment, Have We Understood the User Needs?}

One may wonder why it is still a relatively small community that performs LCA and why LCA has not become more mainstream in business processes, while LCA methodology is used by thousands of companies and has proven to be a relatively robust tool for understanding the impacts of products. Most major multinational companies nowadays have something like an LCA department, which is usually a team of a handful of specialists that perform LCAs mostly to support internal decisions.

To explore this issue we first take a broad perspective of the developments in companies regarding product sustainability; these developments are too often missed by LCA practitioners. Next we will describe our findings from research we

M. Goedkoop $(\bowtie) \bullet$ E. Mieras $\bullet$ A. Gaasbeek $\bullet$ S. Contreras

PRé Consultants, Amersfoort, The Netherlands

e-mail: goedkoop@pre-sustainability.com 
did among corporate LCA practitioners, and finally we will describe how we can link the LCA practitioners to corporate developments to make them more relevant in the business.

\section{Understanding Major Product Sustainability Trends}

About a decade ago, the LCA community was somewhat taken by surprise by the increasing popularity of the cradle to cradle approach. Multi-national companies followed suit; they did in most cases not abandon LCA, but became very active in cradle to cradle. Cradle to cradle now seems to be surpassed in popularity by Circular Economy, partially due to the lack of transparency in the cradle to cradle approach.

Interestingly enough, Circular Economy is also not a very concrete methodology; there is no ISO standard and there are no precise rules. In fact, it misses all aspects we in the LCA world find so relevant. Yet in spite of this, it has gotten a huge uptake with major companies that are even turning around the way their business works. Circular economy is of course more than an assessment method; it is a vision towards a desired future. It tries to transform linear models (produce, distribute, use and dispose) into a circular loop of products. For instance, instead of burning coal and selling electricity, major energy companies are now transforming themselves to be ready for the new reality: electricity is traded between small producers and individuals with solar cells on their roof. While this is a clear example with major sustainability benefits, many ideas in circular economy discussions are not really assessed, and often it is not clear at all what the sustainability merits are.

So what makes these methodologies popular if it is not primarily their ability to measure? What really works is that they present a vision; they tell companies, follow us, follow our guidance and we will not only help you to make products less bad, but we simply turn them into good products, as the cradle to cradle community often said, without ever substantiating what "good" is. And is vision not something which we as the LCA community are often too hesitant about?

\subsection{Understanding “Alternatives” to Life Cycle Assessment}

While LCA aims to be a neutral basis to measure sustainability impacts without having a vision for a desired future, we also see attempts to make LCA more meaningful (Kiron et al. 2015). In December 2013 a large conference around natural capital was organized in Edinburgh and over 500 people joined; many industry leaders and leaders of international organizations all shared their enthusiasm for this new concept called natural capital (or as we say in LCA: monetization). We spotted 
only one other representative from the LCA community. In the meantime, we have seen overviews of more than 100 initiatives to develop natural capital methodologies, all outside the LCA community, all reinventing the wheel and forgetting that the very first serious impact assessment method based on monetization was developed by Bengt Steen in 1989. The big idea is to develop metrics that are understood by the CFO (chief financial officer) and CEO (chief executive officer). Developing metrics that assure results are compelling for the business is probably something the LCA community could learn from.

Another development which is largely missed by the LCA community is the methodology developed by the sustainability consortium. They started out developing an LCA based method to assess products on a large scale, but failed to do so. Therefore, they switched to a procedure that focuses on hotspots and improvement opportunities in the lifecycle. This shift seems to be working very well and we should learn from this.

Coming from another angle, but with the same core idea to make results more meaningful and also to give guidance to the management is the recent discussion to link metrics to planetary boundaries. One idea is to develop a "planetary boundary enabled LCA method". The Stockholm Resilience institute identified eight planetary boundaries, or levels of impacts we should not pass. Initiated by Unilever, a "planetary boundary enabled LCA method" is being developed by a group of experts led by the University of Surrey, with the involvement of Unilever.

\subsection{The Risk of Ignoring These Trends}

In our vision we cannot ignore these trends if we want to ensure a relevant role in policy and business. The assumption in the LCA community is: What gets measured will get managed. This works if managers understand the measurements and can set goals. This works when they talk about revenues, ROI and strategic targets, but what to make of LCA results? Should they set a reduction target of $20 \%$ ? Why 20 ? And why not 5 or $50 \%$ ? They do not have a reference, do not have a gut feeling and often not a clear vision about what LCA results can mean for them. This is what these new concepts do so well; they come with a vision that is understandable, that is actionable and often simply "feels good", or they come with a financial metric that managers (think) they understand, or a reference to something like planetary boundaries. In the case of TSC, the idea is that KPIs and improvement opportunities are based on a general consensus from science, NGO and industry. All these "alternatives" seem often more attractive than an accountancy-like calculation procedure that reports indicators in incomprehensible midpoints. However, there is hope. LCA is the only systematic way to measure, or at least it is much more consistent and transparent than any of these alternatives. 
Table 9.1 Partners and participants in round tables

\begin{tabular}{l|l|l}
\hline Country & Partner organization & Remarks \\
\hline Sweden & Miljögiraff & $\begin{array}{l}\text { Mixture of companies } \\
\text { and research institutes }\end{array}$ \\
\hline Denmark & 2.-0 LCA & High attendance: 10 companies \\
\hline UK & SimaPro UK Ltd & Also consultants \\
\hline France & EVEA & Focused on eco design \\
\hline Italy & 2B & Focus on luxury food companies \\
\hline Germany & GreenDelta & In German language, only in 2012 \\
\hline USA & PRé North America & Only in 2014, several industry associations \\
\hline
\end{tabular}

\section{Understanding the LCA Community Itself}

To develop our understanding of the LCA community, especially the corporate LCA practitioners, we organized a number of workshops in various countries in 2012 and again in 2014.

For this research, we worked together with a number of business partners of our organization in Europe. We asked them to invite their corporate clients to come together for an open discussion on how they see the future of LCA, what their challenges are, and how they cope with them. Of course we also asked them what kind of features and tools would help them most. The meetings were organized in early 2012 and throughout 2014 with seven partners; see Table 9.1.

The majority of the participants were LCA experts working in large multinationals but there were also some researchers and consultants present.

\subsection{The Overarching Message}

Many corporate LCA experts are telling us they have difficulty communicating their findings to the internal stakeholders. One of the problems is that the results are not well understood by their colleagues in marketing, research and product development. It is as if they operate in different worlds. LCA results do not really connect to what their internal clients want to know. This means many are seeking ways to drastically simplify results or translate them into guidelines.

Getting the results out and understood is a problem, getting data in is another big problem. Often other departments are not really motivated to supply data. Getting access to data held by the purchasing department, for example, can be very difficult as they do not see the benefits.

The general picture that emerges is that the LCA department finds it difficult to connect and to be relevant, while at the same time companies have committed themselves to improve the sustainability of products in a rational way. This seems to imply that there is a disconnect between the ambitions of the companies and what 
the LCA experts can offer - do they speak a different language? Or is there another reason that they are not able to connect? This is an intriguing question. This conclusion of a gap between the LCA department and the business was also supported by the results of a quantitative research amongst 274 LCA practitioners in 28 countries conducted by PRé in the second half of 2014.

\section{What's Next: How to Tackle This Chasm?}

As a message to the LCA community and the researchers: the bottleneck is not in the lack of sophisticated tools and methodologies. Companies need LCA departments and practitioners that are better connected with other departments and show genuine interest in alternative approaches. The solution is not to make better LCAs but get a better understanding of what marketing, design, research, purchasing and other departments need.

Based on the round tables, quantitative research and existing scientific research (Frankl 2002) we developed a five-step approach to make the LCA department more relevant:

1. Become a champion for LCA

2. Assure long-term management commitment to sustainability

3. Link LCA with business objectives

4. Find a shared language

5. Jointly explore new applications

These five steps will help LCA departments and practitioners to increase their impact in their company.

\subsection{Become a Champion for Life Cycle Assessment}

Most LCA experts have been trained in technical skills and try to capture reality in a model to see what can make a change. However, technical skills are not sufficient to make a change. We learned from successful LCA practitioners how they are working to become an internal champion, an intrapreneur for LCA, someone who connects with other people and departments, who pleads the cause of LCA and that explores how LCA can contribute to the company's goals.

Business managers want to have as much information as possible to reduce the risk, but know that you never know $100 \%$ for sure. The same holds true for designers, they often work on an idea, a hunch without knowing whether it will work; for instance, they know they have a cost target, but in the early sketch phase they have no way of checking the cost with any precision, so unlike many LCA experts, they are happy with any information that helps them to stay on course and consider the 
environmental impact. A large part of training the designers is about managing (and living with) uncertainties.

Intrapreneurship has some aspects that are quite contradictory to LCA. Perhaps the most important one being that you are not completely sure about the outcomes before you do something. You take a calculated risk. That requires courage and stamina as you do not know what the outcome will be. It also requires the courage to acknowledge that we are imperfect. In businesses, people are used to making decisions with an uncertain outcome, at least to some extent.

To understand how people use the results from an LCA it is important to look at yourself from their perspective. That can change a lot. Just as turning the camera on planet earth - as the astronauts from the Apollo space mission did - had a tremendous impact on how we look at what we do to (the environment on) the earth. A very simple way of doing that is meeting with the users from your LCA study without a specific purpose, drink a cup of coffee and listen to what they are working on, what drives them, what successes they have achieved, and what challenges they face. That will give you great insight in what opportunities LCA can help with. And seizing opportunities is what makes a change.

Knowing what your (internal) clients need - or call it your audience - will also help to present the results in a way that is appealing to them and is relevant for their goals and needs. If you learn how to tell your story, you can convince, motivate and stimulate people to do something with the results from your LCA study. And of course, facts play an important role in that story.

\subsection{Long-Term Management Commitment to Sustainability}

Many big companies have a long term commitment to sustainability. Research (MIT, UNEP and BCG 2015) shows that $42 \%$ of the boards are committed to sustainability and that $31 \%$ of the companies have operational KPIs related to sustainability. Still, support from senior management really is a prerequisite for having an impact; some experienced corporate LCA practitioners have been able to connect to the long-term goals of the company. They learned that management likes facts; facts can help them to make the right, informed decisions about sustainability. And facts are something LCA can deliver, sometimes with some uncertainty, which is something management has learnt to deal with.

Thus, LCA and LCM can play an important role on the road to achieving sustainability goals. We all know the examples of companies that use LCA or LCM in their sustainability strategy. At the same time there are still many companies that do not build their sustainability strategy on sound and robust figures. They follow what others are saying and doing or one of the latest trends with less consistent and transparent methods to measure. So, there is an opportunity for all LCA practitioners because they know the facts and can show something else than what you would expect or what everyone else is doing. 
For companies that already use LCA, top management is not only committed to sustainability, but also to LCA. The survey PRé conducted in 2014 shows that in $57 \%$ of the companies that use LCA, management is aware of LCA. So, LCA is on the agenda in the majority of the companies. Finding an internal sponsor in the (top) management can accelerate the use of LCA in the business. That will definitely help you to deliver value for the business.

\subsection{Shared Language}

Business and LCA have two totally different languages, or as we would say in LCA - nomenclature. As LCA practitioners we know what happens when you do not have the nomenclature right; things get mixed up. So, make sure you understand and capture the language from the people that use your studies (Fig. 9.1).

As Gregory Unruh (2014) puts it in a series "Each functional area has its own conversation built on terminology and jargon suited to their specific business concerns. ....tap into these functional conversations and help managers develop what can be called a sustainability dialect that translates corporate sustainability goals into the local functional discussions and thinking."

Speaking the same language also helps to embed LCA in the core processes of these departments. Only if it is embedded the full potential can be achieved. Only if it is embedded these departments will see and experience the potential of LCA or even sustainability. If not, LCA will probably stay a staff driven "exercise".

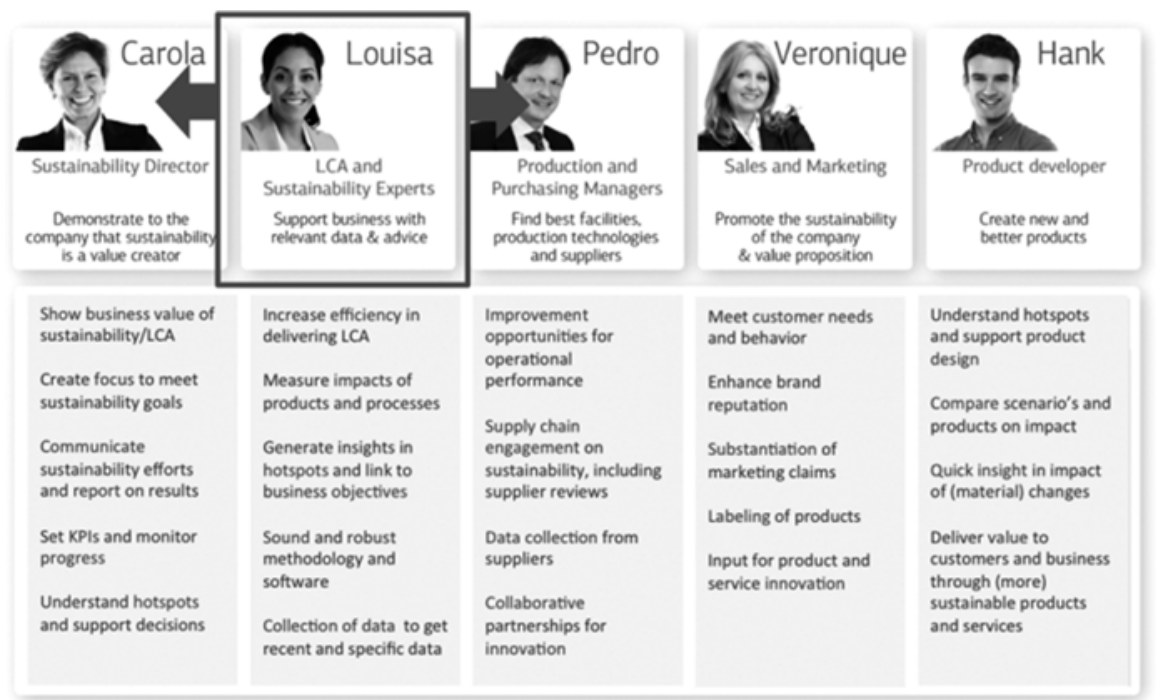

Fig. 9.1 Different needs and language of departments in a company 
This transition is not something that can be achieved overnight. It requires a good radar to sense what is important for people, not only functional but also personal. Sharing - or at least understanding - the same language is really essential to pick up the signals. It also requires a step-by-step approach to link the results from LCA to the objectives and language of these departments or even the corporate strategy.

Next we will describe what such an approach could look like.

\subsection{Link Life Cycle Assessment with Business Objectives}

In most companies, sustainability goals are set top-down. In the corporate sustainability strategy, goals are set for energy, water and climate change, for example. Business units and departments are then given the task to achieve these goals and start various projects to realize these goals in the timeframe given. The projects are topic, location or process specific and do not take trade-offs into account. Based on the goals, companies want to measure the results to report on them and improve their performance. Often it turns out to be quite hard to report and improve the goals. They were not really substantiated by insights on a business and product level which is where the improvements have to be achieved (left column of Fig. 9.2), and let alone the negative trade-offs these improvements could have.

LCA is much more a bottom-up approach as it starts at a product level. In the product or service life cycle it is identified where a product has its impact. LCA can deliver insights in what impacts occur for each impact category and life cycle stage. It enables us to identify hotspots and improvement opportunities, from material selection to pinpointing the most impactful supplier, from process innovations to contributions of each phase. However, at the same time LCA struggles to link these hotspots and improvement opportunities to the KPIs of the company (see column 2 of Fig. 9.2), especially as these are often formulated in a different language. TSC has done some great work to link hotspots to KPIs, but adding the top-down route is essential to make it company specific and meaningful for management. An integrated approach provides a unique opportunity to achieve maximum alignment of product and corporate strategies (Furfori et al. 2014).

To increase the impact of LCA, the LCA practitioner and the LCA department need to connect the dots. To take the lead in this you can create an overview of business and project KPIs and combine these with the hotspots you identified through LCA studies (Fig. 9.2). Based on those insights and KPIs, projects for improvement can be identified. This approach helps to link the product level with the business/ corporate level. It brings together the sustainability insights on a corporate and product level. By doing this you can identify sweet spots, overlap in hotspots as well as blind spots. It also brings together different departments when it shows they need to collaborate to achieve their goals. The same applies for suppliers; based on the hotspots the most relevant suppliers for the sustainability goals - which is not the same as the most important suppliers in terms of costs - can be pinpointed. By doing this the sustainability strategy gets more substantiated and goals become 


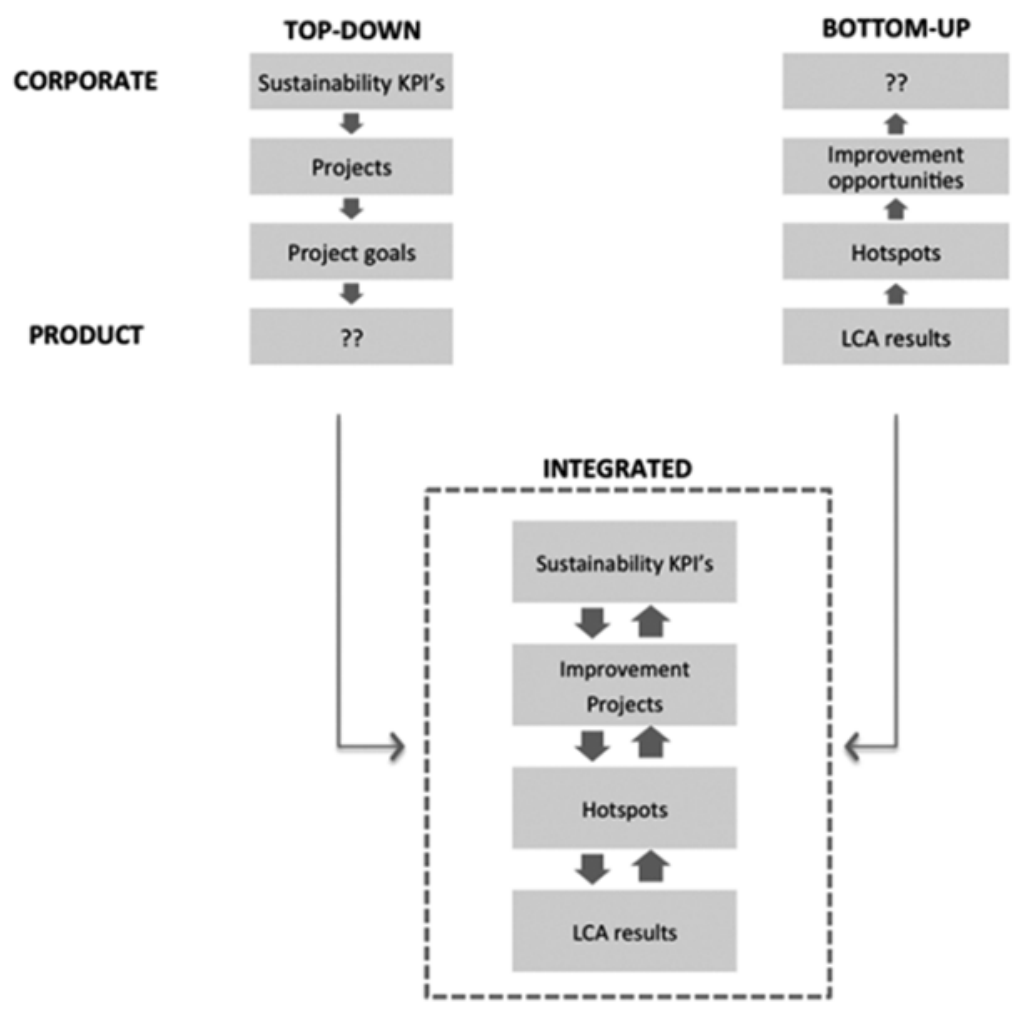

Fig. 9.2 A top-down and bottom-up approach to link LCA results and business objectives

more realistic. By forming new partnerships with suppliers or customers and stimulating cross-company collaboration, innovation can be spurred.

LCA can play an instrumental role in the further implementation of these improvement projects, but do not hesitate to use other tools if needed. Once it has been embedded in the processes, the next step is to set up the infrastructure to facilitate this and to explore new opportunities to create value. The latter can only be done if you are a trusted business partner within your company.

\subsection{Jointly Explore New Applications}

Over the past few years a number of studies have been published about the use of LCA in business (amongst others Chun and Lee 2013; Piekarski et al. 2013). These studies identified the several ways LCA can be used. Some of the studies also identified for which departments the studies could be used. What is missing in those studies is the combination of the two. So, what use is relevant for a specific department? 


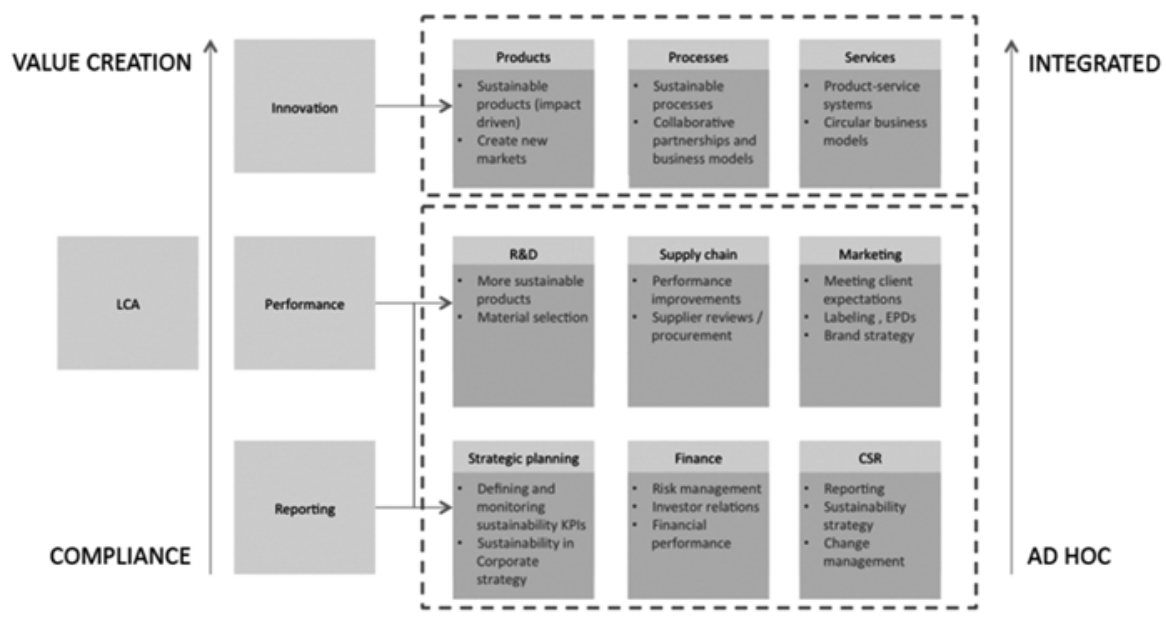

Fig. 9.3 Applications of LCA in (different departments of) a company, inspired by Moro Piekarski (2013)

We tried to represent that in Fig. 9.3 below, which was inspired by the study of Moro Piekarski. In your daily practice this is something you need to investigate.

Apart from the type of use, it is important to look at how it is used (ad hoc vs. integrated) and why it is used (reporting, performance improvement or value creation). The overall purpose - or the why question - is related to the corporate sustainability strategy: is it aimed at compliance and reducing risk or is the goal to create shared value. The more it is aimed at value creation, the more LCA should be integrated in the business. Is it more directed at compliance and reporting, LCA probably stays more ad hoc. Reporting and improving performance can be done on a department level, innovation requires a more integrated and holistic approach.

To develop these specific applications for LCA it is essential to link up with people from these departments to explore the needs and opportunities - remember the personas we presented earlier. In some companies they recognized this need and created a specific position to liaise between the LCA department and the internal client. In a transition phase this could be a good solution.

\section{Conclusions}

LCA has developed into a sound and robust methodology that is probably the best approach available to measure social and environmental impact. Within the LCA community there are a lot of talented and motivated people to make a change. We saw how LCA practitioners expand their own ecosystem and step out of their comfort zone based on facts and how this increased the impact they have. 
We have given a five-step approach to become more relevant and step into a world that identifies opportunities to create sustainable value. However, our best advice is listening, and especially listening to those outside the LCA community, the people who are engaged, in what we have called "alternatives" and of course the departments that could benefit from LCA. What matters is whether you can provide a basis for rational decision-making by the business that will result in sustainable products and services as well as business value.

Open Access This chapter is distributed under the terms of the Creative Commons Attribution Noncommercial License, which permits any noncommercial use, distribution, and reproduction in any medium, provided the original author(s) and source are credited.

\section{References}

Chun Y-Y, Lee K-M (2013) Life cycle-based generic business strategies for sustainable business models. J Sustain Dev 6(8)

Frankl P (2002) Life cycle assessment as a management tool. In: Ayres RU, Ayres LW (eds) A handbook of industrial ecology. Edward Elgar, Cheltenham

Furfori S, Antonini V, Breedveld L (2014) The link between LCA and CSR with espresso coffee as an example. In: 9th international conference LCA of food, San Francisco. 8-10 Oct

Kiron D, Kruschwitz N, Haanaes K, Reeves M, Fuisz-Kehrbach SK, Kell G (2015) Joining forces, collaboration and leadership for sustainability. http://sloanreview.mit.edu/projects/ joining-forces/

Piekarski CM, Mendes da Luz L, Zocche L, De Francisco AC (2013) Life cycle assessment as entrepreneurial tool for business management and green innovations. J Technol Manag Innov $8(1): 44-53$

Unruh G (2014) Sustainability dialects. http://sloanreview.mit.edu/article/sustainability-dialects/ 